\title{
Bridges to STEM Careers: Hands-on Student Activities
}

\section{Dr. Sadegh Davari, University of Houston, Clear Lake}

Dr. Sadegh Davari, Professor of Computer Science and the Chair of Division of Computing and Mathematics in the School of Science and Computer Engineering at the University of Houston-Clear Lake, 2700 Bay Area Blvd, Houston, Texas 77058; (281) 283-3865; Davari@uhcl.edu.

Prof. Nathanial David Wiggins, San Jacinto College

Ms. Krishani Abeysekera, University of Houston, Clear Lake

Krishani Abeysekera received her Master of Science in Computer Science from the University of Houston Clear Lake, in May 1995. Currently, she is a Senior Lecturer/Systems Administrator for the School of Science and Engineering at UHCL. She is also the Program Chair of the Information Technology program. Her research interests include Computer Forensics, Security and Graphics.

Prof. Sharon P Hall, University of Houston, Clear Lake 


\title{
Bridges to STEM Careers: Hands-on Students Activities
}

\begin{abstract}
The Bridges to STEM Careers (BSC) project is funded by the NSF STEP program. The project is a collaborative effort between a university and three community college campuses. The main goals of the project are to increase attainment of STEM associate and baccalaureate degrees, as well as to facilitate and increase transfer of STEM students across the institutions. The project focuses on increasing student engagement and persistence through the development of face-toface and technology-enhanced learning networks, both within and across campuses. Supporting initiatives include summer orientation programs, career-awareness and enhancement activities, and opportunities for hands-on extra-curricular activities. In this paper we will provide a brief overview of hands-on student activities and the lessons learned so far.
\end{abstract}

\section{Introduction}

The Bridges to STEM Careers (BSC) is a collaborative five-year project between a university and three community college campuses funded by the NSF STEP program. Our goal is to give students opportunities for learning by doing, thereby increasing students' interest in the field and confidence in their own abilities. The university and community college partners work together to plan, execute and assess events that further students' knowledge, skills and capabilities.

Students interact closely with their peers, faculty, and industry partners at each event. The overall goal of the project is to increase the number of well-educated STEM graduates for the benefit of local and global economy. One of the primary obstacles students face in degree attainment is lack of engagement with peers, faculty, campus services and career opportunities ${ }^{1,2}$. This is addressed through team-building and project-based activities that involve students from all four campuses. Technology is the theme of our project and we have been focusing on the following STEM Fields: Computer Science, Computer Engineering, Computer Information Systems, Information Technology, and Mathematics.

The main goals of our project are to increase attainment of STEM majors in baccalaureate and associate degree granting institutions, to facilitate and increase transfer of STEM majors from community college to university, to increase student engagement and persistence through the development of face-to-face and technology-enhanced learning communities, and to collaborate with industry professionals.

Supporting initiatives for this project include peer mentoring and tutoring, summer bridge program, Tech Fridays, annual STEM challenge with participation and sponsorship from local industry, BSC student clubs on four campuses, and communication through the on-line cybercenter. Peer mentoring and hands-on experiences with technology have shown to encourage students to choose and succeed in STEM fields ${ }^{1,2}$. Activities are planned and executed by student mentors with oversight by the PIs and co-PIs. 
Assessment by the external evaluator of our project has shown that students who have participated in these activities have gained confidence to continue in their STEM education. Our observations indicate that participating students can relate better and feel more comfortable asking questions of other students than asking faculty.

Our project elements are based on literature-based best practices ${ }^{3}$ and successful pilot studies ${ }^{4,5}$. Student mentors of the project are given opportunities to get directly involved in organizing activities and taking leadership roles at events. Student participants are provided opportunities to practice teamwork and be introduced to emerging technologies such as robotics, mobile application development, computer forensics, cyber security, computer game programming, web design, and video editing.

\section{$2 \quad$ Hands-on Project Activities}

The BSC Executive team, comprising PIs and co-PIs from all campuses, meets each month to plan and coordinate project activities. A main goal for student activities is to make students from other campuses feel welcomed, particularly those from the partnered community colleges, so that they might be more inclined to attend the university and complete a bachelor's degree.

\subsection{Peer Mentors}

Each campus has a team of students who have various responsibilities, including tutoring; planning and executing BSC activities; and preparing and administering the annual programming challenge. Mentors are selected from a pool of outstanding and enthusiastic students from different majors including computer science, computer engineering, computer information systems and mathematics. They have a broad range of experience with technology and academics.

\subsubsection{In-class Peer Mentoring}

Student mentors attend targeted classes and serve as in-class mentors. At the university level, two new 4-hour courses have been developed for computer science and information systems students: Computer Science I (CS1) and Computer Science II (CS2). The courses were designed to allow more time for in-class hands-on exercises and to help with student success. During inclass exercises, mentors provide students with one-on-one guidance in computer programming design and with debugging and execution of programs. Mentors also provide suggestions for programming assignments and in-class exercises. By attending each class, mentors build a rapport with students and get an understanding of how to best help each individual.

Student mentoring in math classes at the community college level was coupled with a pilot course for algebra with a lab component for active engagement. The three credit, four hour College Algebra was designed to enhance student success by using a Marzano Taxonomy approach to problem solving by scaffold structures in learning. Mentors quietly assist struggling students during mini-lectures so that concepts can be taught. Group work time and in-class competitions were held by peer mentors so that faculty can focus on struggling students. Two faculty members taught the courses and also taught regular courses, allowing for a control. The additional hour was placed as conference, so no additional time was charged to the college or 
student. Success rates in peer mentored to control and other traditional courses showed an increase of $7 \%$ using the census roll in comparison to final A-C grades. Additionally, targeted enrollment shows classes of greater than $80 \%$ success rates.

\subsubsection{Out-of-class Peer Mentoring}

Mentors hold office hours which cover most of the school's hours from Monday through Friday. Students stop by to get help with any of their computing, mathematics or engineering courses. While the courses have assigned graduate teaching assistants with office hours, we have found that students prefer to meet with the undergraduate mentors when they have questions.

Since mentors also attend and participate in the CS1 and CS2 classes, they are familiar with the class material and know the expectations of the instructor. This results in the outside mentoring sessions being more effective.

\subsubsection{Weekly Recitation Sessions}

Mentors hold weekly recitation sessions on key topics that supplement student learning in computing, engineering and mathematics such as review of number systems, logic and truth tables, stacks and queues. Mentors alternate on topics, so that all of them get exposure to designing recitation sessions and teaching.

\subsection{Tech Fridays}

Tech Fridays are designed by mentors and faculty to create learning opportunities. Industry and academic speakers are invited to provide relevance. Tech Fridays are held for three hours and consist of hands-on activities, worksheets and interaction with topic experts.

To date, we have offered eight Tech Friday events. Topics included:

- Robotics: students worked with Arduino boards and sensors.

- Computer Forensic Investigation: students worked on solving a simulated case using forensic software tools ${ }^{6}$. A Houston police officer talked with students about his experience as a computer forensics specialist.

- Raspberry Pi: students learned programming concepts using Raspberry Pis.

- Web Development: students were taught how to develop web pages. An experienced professional was invited to give background and a lecture on careers in web development.

- Video Editing: students learned how to edit sound, image, and video using free software.

- Arduino and Charlieplexing: students wired LEDs and wrote programs to generate light sequencing.

- Game Programming: students developed a computer game.

- Sound to Light: students wired kits to convert sound to light.

The events are usually at capacity with 35 to 50 students attending each event. 


\subsection{Programming Challenge}

Each spring semester teams are invited to the University for a Programming Challenge. The challenges require teams to participate in three stations and complete several tasks in each station in succession, with increasing difficulty. Teams are categorized as beginner or advanced level. Events are timed and checked for completion.

Participants consisted of students from local high schools, community colleges, and universities. Several home schooled and middle school students heard about the event and participated.

The theme of the first challenge was robotics programming and the three stations consisted of:

- Controlling Arduino and lights to produce Morse codes

- Reading sensor data such as temperature and water

- Moving a robotic tank through an obstacle course.

The second challenge was based on general STEM skills and the three stations consisted of:

- Game of Clues to challenge their math knowledge

- Creative Inventors to showcase their imaginative skills

- Robot Adventure to test their problem solving and programming skills

Winning teams were offered summer internships with local industry. Scholarships to the university and prizes were given to category winners. Raffle prizes were given to every participant.

Local industries and businesses sponsored and provided prizes. Industry partners and faculty served as judges and technical program supervisors.

The events have always been at capacity. The robotics challenge hosted 15 teams, and the STEM challenge hosted 18 teams, with a maximum of 4 participants per team.

\subsection{Extended Orientation}

A 3-day extended summer orientation has been offered twice so far. The orientation brings together students from various stages of their STEM education. The first day is for community college students and is held at each of the three community college campuses. Students are introduced to the campus, student leaders and faculty. On the second day the community college students convene at one of the community college campuses and new STEM majors of the university convene at the university. A motivational speaker presents at the community college campus. At the university students participate in a scavenger hunt to get familiar with the campus. They also engage with a faculty panel, a student mentor panel, and are assigned to specific BSC mentors. On the third day all student participants convene at the University for Team Building Activities. They engage with a panel of academic and transfer advisers, financial aid officers, and student services representatives.

Each day is a morning event that ends with lunch at noon. All students receive prizes and giveaways. Of the students who attended the 2014 orientation, $84 \%$ said that they felt more 
confident about their transition to college as a result of attending and $100 \%$ said they would recommend the orientation to a fellow student.

\section{Internal/External Advisory Board Meetings}

The project is governed by internal and external advisory boards that meet with the BSC executive team. We have been meeting with the external board members annually and the internal board members every semester to report progress and to receive feedback and advice. Actions have been taken as a result of recommendations made by the internal and external advisory boards.

In response to suggestions by the external advisory board for creating industry-driven group projects, advanced interdisciplinary projects have been implemented and supported by the BSC project $^{7,8}$.

\section{External Evaluator}

The BSC project has an external evaluator who evaluates the effectiveness of major project activities. The evaluator collects a mix of qualitative and quantitative data. The qualitative data is collected via face-to-face interviews with students, open-ended survey questions, and observations during the events. The quantitative data is collected via pre and post surveys that measure students' preparedness, self-perceived aptitude, and attitudes/interest pertaining to STEM. The evaluator stays in compliance with all university IRB restrictions. Survey data is analyzed and the results are provided to the BSC Executive team for possible actions and it is reported to NSF in our annual reports.

\section{$5 \quad$ Conclusions and Lessons Learned}

Collaboration with the participating colleges has strengthened relationships between students, faculty and administration within all campuses.

All activities have been assessed by and external evaluator. Events have been at maximum capacity and assessment results show that the activities have been well received.

Based on the first two years of activities, we have made the following observations:

1. Students will make time to attend BSC events if there are hands-on opportunities to learn about STEM topics.

2. Tech Fridays provide students an opportunity to build relationships with other students interested in STEM careers.

3. The Robotics Programming Challenge and the STEM Challenge motivates our students to take on more challenging projects in computer hardware, robotics, and programming.

4. Students have a chance to meet faculty and students from all campuses, and engage with industry partners during BSC events.

5. Industry partners have the opportunity to engage with students, gauge student and BSC program accomplishments, and provide mentorship.

6. Having the opportunity to design and carry out teambuilding events builds self-confidence and provides BSC mentors with leadership and event planning experience. 


\section{References}

1. Jolly, Campbell, and Perlman, "Engagement, Capacity and Continuity: A Trilogy for Student Success" (GE Foundation, September 2004)

2. Chun-Mei Zhao and George D. Kuh, "ADDING VALUE: Learning Communities and Student Engagement", Research in Higher Education, vol. 47, 2006, pp 89-109

3. American Society for Engineering report, "Going the Distance: Best Practices and Strategies for Retaining Engineering, Engineering Technology and Computing Students" (Washington, D.C., 2012)

4. Davari, S., Abeysekera, K. and Yue, K., "Building STEM Awareness through Programming Competition", the Fourth Annual Texas Engineering and Technology Consortium Best Practices Conference, Austin, February 1112,2009

5. Abeysekera, K., Davari, S., Yue, K., Brown, E., Kent, M., Betts, P., \& Meeks, J., Success through Academic Recognition (STAR): Sustaining and Expanding UHCL and SJC TWD Computer Science Scholar Program, the third annual Texas Engineering and Technology Consortium Best Practices Conference, Dallas, Feb. 28, 2008, pp 7-9. www.thecb.state.tx.us/index.cfm?objectid=8828378A-D358-8867-5E14BDC65C9860B9

6. Abeysekera, K., Zhang, T., Perkins-Hall, S., Davari, S., "Creating awareness of the field of cyber forensics with a simulated digital crime scene investigation", 19th Annual Colloquium for Information Security Education (CISSE), June 14, 2015, Las Vegas, NV.

7. Wiggins, Perkins-Hall, et. al, "First Year Engineering Experience, Resource Management in Completion of an Arduino Engineering Project and Its Industrial Applications", First Year Education Experience Conference, College Station, TX, August 7-8, 2014.

8. Wiggins, Yue, et. al, "Microgravity Science and Technology, Acoustic Flame Suppression Mechanics in a Microgravity Environment”, Microgravity Science and Technology, March 21, 2015.

Acknowledgement: This work is supported in part by the National Science Foundation award: DUE-1317490 